\title{
Which user errors matter during HIV self- testing? A qualitative participant observation study of men who have sex with men (MSM) in China
}

\author{
Chongyi Wei ${ }^{1 *}$, Li Yan², Jianjun Li ${ }^{3}$, Xiaoyou Su ${ }^{4}$, Sheri Lippman ${ }^{5}$ and Hongjing Yan $^{3}$
}

\begin{abstract}
Background: The World Health Organization recommends HIV self-testing (HIVST) as an additional approach to HIV testing services. We aimed to assess to what extent HIVST was conducted correctly by Chinese men who have sex with men (MSM) and to identify user errors during the HIVST process in order to inform strategies to optimize its use and thus reduce the number of undiagnosed HIV infections.

Methods: Between February and March 2017, participant observations were conducted with 27 MSM in an east coastal city in China. In the presence, but without the assistance or orientation, of a trained HIV testing counselor, participants conducted HIVST (either finger prick or oral fluid) according to manufacturers' instructions. Errors were recorded on checklists during direct observation and double checked afterwards by reviewing video files of the observations.

Results: Overall, 12 participants (44.4\%) had invalid test results due to user errors. Just five (18.5\%) did not make any errors during the entire HIVST process. Failure to follow all the steps based on manufactures' instructions was a common problem for both finger prick and oral fluid self-testers. For finger prick users, most errors occurred during the stage of collecting the specimen. In contrast, oral fluid users made most errors during the stage of testing the collected specimen.
\end{abstract}

Conclusions: Although we found that user errors were common among MSM administering HIVST, this should not deter or discourage routine implementation and scale-up of HIVST as strategies can be implemented to facilitate the correct use of HIVST.

Trial registration: This study was a part of a clinical trial: ClinicalTrials.gov (\#NCT02999243); Registration date: December 20, 2016.

Keywords: HIV, Self-testing, HIV testing, Men who have sex with men

\section{Background}

HIV self-testing (HIVST), the process in which a person collects his/her own specimen (oral fluid or blood) and then performs an HIV test and interprets the results in private, is recommended by the World Health Organization as an additional approach to HIV testing services [1]. Review of evidence demonstrated that HIVST was highly acceptable to

\footnotetext{
* Correspondence: Chongyi.Wei@rutgers.edu

${ }^{1}$ Department of Social and Behavioral Health Sciences, Rutgers School of Public Health, 683 Hoes Lane West, Office 312, Piscataway, NJ 08854, USA Full list of author information is available at the end of the article
}

many users including key populations, more than doubled uptake of HIV testing among men who have sex with men (MSM), could result in identifying an equivalent or greater proportion of HIV-positive individuals, and could achieve acceptable sensitivity $(80-100 \%)$ and specificity $(95-100 \%)$ [2-5]. This timely recommendation can help attain the first of the United Nation's 90-90-90 targets, as many individuals remain unaware of their HIV serostatus [6].

HIVST is particularly suitable for expanding HIV testing services among MSM, who are disproportionally affected by HIV, and do not always access facility-based testing in

(c) The Author(s). 2018 Open Access This article is distributed under the terms of the Creative Commons Attribution 4.0 International License (http://creativecommons.org/licenses/by/4.0/), which permits unrestricted use, distribution, and reproduction in any medium, provided you give appropriate credit to the original author(s) and the source, provide a link to the Creative Commons license, and indicate if changes were made. The Creative Commons Public Domain Dedication waiver (http://creativecommons.org/publicdomain/zero/1.0/) applies to the data made available in this article, unless otherwise stated. 
contexts where MSM-related stigma and discrimination are prevalent [2, 7-9]. MSM account for a third and rising proportion of new HIV infections in China, which is in part due to lack of regular testing $[10,11]$. Although not officially endorsed by the Chinese health authorities, HIVST kits are readily accessible through some community-based organizations and can be easily purchased on the Internet. Several recent cross-sectional surveys of Chinese MSM reported that between 20 and 29\% of participants had ever self-tested for HIV [12-14]. Furthermore, one study found that $59 \%$ of men who self-tested reported HIVST as their first HIV testing experience [12].

As substantial numbers of Chinese MSM are already using HIVST, it is important to ensure that the tests are used correctly to improve diagnostic accuracy, especially in an unregulated market where quality of HIVST kits can vary. In fact, a study reported that just $24 \%$ of Chinese MSM who ever self-tested said they were "very confident" in the accuracy of their test results and $73 \%$ perceived self-testing to be less accurate compared to facility-based testing [13]. Therefore, this participant observation study aimed to assess to what extent HIVST was conducted correctly by Chinese MSM and to identify common user errors during the HIVST process. Such findings can inform strategies to optimize HIVST use and thus reduce the number of undiagnosed HIV infections.

\section{Methods}

Between February 25th and March 5th, 2017, participant observations were conducted with $27 \mathrm{MSM}$ in an east coastal city in China. Purposive sampling was used to recruit a diverse group of participants in terms of age, education and history of HIV testing. Participants were recruited through referrals from two local community-based organizations (CBOs) which offer HIV prevention services to MSM. To be eligible, participants had to be born male, 18 years old or older, a local resident, speak either Mandarin or the local dialect, have had sex with another male in the past 12 months, and self-report being HIV-negative or unknown status.

Participant observations were conducted in a private room at the Provincial Center for Disease Control and Prevention (CDC). Two types of HIV self-testing kits, finger prick (AIJI Colloidal Cold, HIV-1/2, NewScen Coast Bio-Pharmaceutical Co., Ltd., Tianjin, China) and oral fluid (Aware HIV-1/2 OMT, Beijing Marr Bio-Pharmaceutical Co., Ltd., Beijing, China), were offered to participants where they could choose to use either one based on preference. In the presence, but without the assistance or orientation, of a trained HIV testing counselor, participants conducted self-testing procedures according to the manufacturers' text- and pictorial-based instructions. During the direct observations, the counselor recorded errors made by the participants using two checklists (one for each type of HIVST. Please see Additional files 1 and 2 for the checklists). Each participant observation was also video recorded. A research assistant reviewed the videos afterwards and double checked to ensure that the user errors were correctly marked on the checklists. All participants conducted a second HIVST with the assistance of the counselor after completing the self-testing procedures on their own. Participants who tested preliminary positive were offered

Table 1 Socio-demographic and behavioral characteristics of MSM participants $(N=27)$

\begin{tabular}{|c|c|}
\hline & n (\%) \\
\hline \multicolumn{2}{|l|}{ Age } \\
\hline $18-19$ & $1(3.7 \%)$ \\
\hline $20-29$ & $17(63.0 \%)$ \\
\hline $30-40$ & $9(33.3 \%)$ \\
\hline \multicolumn{2}{|l|}{ Educational level } \\
\hline High school or below & $7(25.9 \%)$ \\
\hline Some college & $9(33.3 \%)$ \\
\hline College or above & $11(40.7 \%)$ \\
\hline \multicolumn{2}{|l|}{ Marital status } \\
\hline Single & $24(88.9 \%)$ \\
\hline Married & $1(3.7 \%)$ \\
\hline Divorced/separated & $2(7.4 \%)$ \\
\hline \multicolumn{2}{|l|}{ Employment status } \\
\hline Full-time & $18(66.7 \%)$ \\
\hline Part-time & $1(3.7 \%)$ \\
\hline Student & $7(25.9 \%)$ \\
\hline Unemployed & $1(3.7 \%)$ \\
\hline \multicolumn{2}{|l|}{ Sexual orientation } \\
\hline Gay & $16(59.3 \%)$ \\
\hline Bisexual & $9(33.3 \%)$ \\
\hline Heterosexual & $0(0 \%)$ \\
\hline Unsure & $2(7.4 \%)$ \\
\hline \multicolumn{2}{|c|}{ Have a main male sex partner } \\
\hline Yes & $12(44.4 \%)$ \\
\hline No & $15(55.6 \%)$ \\
\hline \multicolumn{2}{|c|}{ Condomless anal sex in the past 6 months } \\
\hline Yes & $8(29.6 \%)$ \\
\hline No & $19(70.4 \%)$ \\
\hline \multicolumn{2}{|l|}{ Ever tested for HIV } \\
\hline Yes & $14(51.9 \%)$ \\
\hline No & $13(48.1 \%)$ \\
\hline \multicolumn{2}{|l|}{ Ever self-tested for HIV } \\
\hline Yes & 9 (33.3\%) \\
\hline No & 18 (66.7\%) \\
\hline
\end{tabular}


confirmatory testing on site. The provincial CDC followed up with diagnosed HIV-positive individuals for CD4 and viral load testing and referred them to the local designated hospital for treatment.

Participation in the study was anonymous and voluntary. An incentive of 100 RMB ( 15 USD) was offered to compensate for participants' time and effort. The study was approved by the University of California San Francisco, Rutgers University and Jiangsu Provincial CDC's Institutional Review Boards.

\section{Results}

A total of 27 eligible men participated in the study. A majority $(63.0 \%)$ of participants were between the ages of 20 and 29. About three quarters either completed some college (33.3\%) or had an educational level of college or above (40.7\%). Most (88.9\%) were single/never married. Over half $(59.3 \%)$ self-identified as gay while a third (33.3\%) self-identified as bisexual. About half (44.4\%) reported that they had a main male sex partner at the time of this study. Just under a third (29.6\%) reported condomless anal sex in

Table 2 Numbers of errors made by MSM participants during HIV self-testing process and results of self-testing and retest ( $N=27)$

\begin{tabular}{|c|c|c|c|c|c|c|c|c|c|}
\hline \multicolumn{10}{|c|}{ HIV self-testing modality: Finger prick $(N=15)$} \\
\hline \multirow[t]{2}{*}{ Participant \# } & \multirow[t]{2}{*}{ Age } & \multirow[t]{2}{*}{ Education } & \multirow{2}{*}{$\begin{array}{l}\text { HIV testing } \\
\text { history }\end{array}$} & \multicolumn{4}{|c|}{ Numbers of errors made } & \multirow[t]{2}{*}{ Test result } & \multirow[t]{2}{*}{ Retest } \\
\hline & & & & $\begin{array}{l}\text { Preparing the } \\
\text { test }(n=0-2)\end{array}$ & $\begin{array}{l}\text { Administering the } \\
\text { test }(n=0-4)\end{array}$ & $\begin{array}{l}\text { Interpreting the } \\
\text { result }(n=0-1)\end{array}$ & $\begin{array}{l}\text { Total } \\
(n=0-7)\end{array}$ & & \\
\hline 1 & $18-29$ & Some college & Ever self-tested & 2 & 2 & 0 & 4 & Negative & Negative \\
\hline 2 & $18-29$ & $\geq$ College & Ever self-tested & 1 & 2 & 0 & 3 & Negative & Negative \\
\hline 3 & $18-29$ & Some college & Ever self-tested & 0 & 3 & 1 & 4 & Invalid & Negative \\
\hline 4 & $30-40$ & Some college & Ever self-tested & 1 & 1 & 0 & 2 & Negative & Negative \\
\hline 5 & $18-29$ & $\geq$ College & Ever self-tested & 0 & 1 & 1 & 2 & Invalid & Negative \\
\hline 6 & $30-40$ & Some college & Ever self-tested & 1 & 2 & 1 & 4 & Invalid & Negative \\
\hline 7 & $18-29$ & Some college & Ever self-tested & 1 & 2 & 0 & 3 & Negative & Negative \\
\hline 8 & $30-40$ & $\geq$ College & Ever self-tested & 1 & 1 & 0 & 2 & Negative & Negative \\
\hline 9 & $18-29$ & $\geq$ College & Ever tested $^{\mathrm{a}}$ & 0 & 0 & 0 & 0 & Negative & Negative \\
\hline 10 & $18-29$ & $\leq$ High school & Never tested & 1 & 4 & 1 & 6 & Invalid & Negative \\
\hline 11 & $18-29$ & $\geq$ College & Never tested & 1 & 2 & 0 & 3 & Positive & Positive \\
\hline 12 & $30-40$ & $\leq$ High school & Never tested & 0 & 3 & 1 & 4 & Invalid & Negative \\
\hline 13 & $18-29$ & $\geq$ College & Never tested & 0 & 3 & 0 & 3 & Negative & Negative \\
\hline 14 & $18-29$ & $\geq$ College & Never tested & 0 & 3 & 0 & 3 & Negative & Negative \\
\hline 15 & $18-29$ & $\geq$ College & Never tested & 0 & 2 & 1 & 3 & Invalid & Negativ \\
\hline
\end{tabular}

HIV self-testing modality: Oral fluid $(N=12)$

\begin{tabular}{|c|c|c|c|c|c|c|c|c|c|}
\hline & & & & Numbers of er & ors made & & & & \\
\hline & & & & $\begin{array}{l}\text { Preparing the } \\
\text { test }(n=0-3)\end{array}$ & $\begin{array}{l}\text { Conducting the } \\
\text { test }(n=0-7)\end{array}$ & $\begin{array}{l}\text { Interpreting the } \\
\text { result }(n=0-2)\end{array}$ & $\begin{array}{l}\text { Total } \\
(n=0-12)\end{array}$ & & \\
\hline 16 & $18-29$ & $\leq$ High school & Ever self-tested & 3 & 6 & 2 & 11 & Invalid & Negative \\
\hline 17 & $30-40$ & $\leq$ High school & Ever tested $^{a}$ & 1 & 4 & 0 & 5 & Negative & Negative \\
\hline 18 & $18-29$ & Some college & Ever tested $^{\mathrm{a}}$ & 1 & 7 & 2 & 10 & Invalid & Negative \\
\hline 19 & $18-29$ & $\geq$ College & Ever tested $^{\mathrm{a}}$ & 0 & 2 & 2 & 4 & Invalid & Negative \\
\hline 20 & $30-40$ & $\geq$ College & Ever tested $^{\mathrm{a}}$ & 0 & 0 & 0 & 0 & Negative & Negative \\
\hline 21 & $30-40$ & $\leq$ High school & Never tested & 1 & 6 & 2 & 9 & Invalid & Negative \\
\hline 22 & $18-29$ & Some college & Never tested & 0 & 0 & 0 & 0 & Negative & Negative \\
\hline 23 & $18-29$ & $\leq$ High school & Never tested & 1 & 6 & 2 & 9 & Invalid & Negative \\
\hline 34 & $18-29$ & $\geq$ College & Never tested & 0 & 0 & 0 & 0 & Negative & Negative \\
\hline 25 & $30-40$ & Some college & Never tested & 0 & 0 & 0 & 0 & Negative & Negative \\
\hline 26 & $30-40$ & $\leq$ High school & Never tested & 0 & 4 & 2 & 6 & Positive & Positive \\
\hline 27 & $18-29$ & Some college & Never tested & 0 & 3 & 1 & 4 & Invalid & Negative \\
\hline
\end{tabular}

${ }^{\mathrm{a}}$ At a facility (e.g., $\mathrm{CDC}, \mathrm{CBO}$, hospital), excluding self-testing 
the past 6 months. In terms of history of HIV testing, 48.1\% had never been tested for HIV while 33.3\% said they had conducted HIV self-testing before (Table 1).

Of the 27 participants, 15 (55.6\%) chose to use finger prick self-testing while the rest (44.4\%) preferred oral fluid (Table 2). Overall, 12 (44.4\%) had invalid test results due to user errors but were all re-tested as HIV-negative. Just five (18.5\%) did not make any errors during the entire HIV self-testing process. Two (7.4\%) self-tested positive and were re-tested HIV-positive.

Among finger prick self-testers, 6 (40.0\%) had invalid test results (Table 2). Only one participant (6.7\%) did not make any error, who was a frequent HIV tester although never self-tested before. Among those who made errors, total numbers of errors ranged from two to six (maximum $=7$ ). During the stage of administering the test, a majority $(10 / 14,71.4 \%)$ made two or three errors (maximum $=4$ ). The most common errors included: difficulties in using the lancet and the micro pipette to draw blood; insufficient amount of blood drawn from finger; and failure to follow all the steps. Notably, of the 8 participants who self-tested before, three (37.5\%) had invalid test results and all made some errors during the process.

Among oral fluid self-testers, 6 (50.0\%) had invalid test results (Table 2). Four participants (33.3\%) did not make any error. Among those who made errors, total numbers of errors ranged from four to 11 (maximum $=12$ ). During the stage of administering the test, a majority $(6 / 8$, $75.0 \%$ ) made four or more errors (maximum $=7$ ). The most common errors included: failure to follow all the steps; removing the membrane surface from the assay test strip; and placing the test strip upside down in the tube containing the diluted specimen.

\section{Discussion}

This participant observation study found that when unassisted, a majority of Chinese MSM participants made some user errors during the process of conducting HIVST. Some of the errors were significant enough that almost half of the test results were rendered invalid. Our finding is consistent with prior research that sensitivity of HIVST was reduced among individuals in unsupervised or unassisted settings $[5,15]$. Failure to follow all the steps according to manufactures' instructions was a common problem for both finger prick and oral fluid self-testers. For finger prick users, most errors occurred during the stage of collecting the specimen. In contrast, oral fluid users made most errors during the stage of testing the collected specimen.

There were no clearly discernible patterns between participants' histories of HIV testing and numbers of user errors or self-testing results; having previously tested for HIV did not facilitate the conduct of HIVST. In fact, a third of the invalid test results were observed among participants who self-tested before. It did appear, however, that participants with lower educational level were more prone to making errors. Of the 7 men who completed high school or below, almost three quarters $9(5 / 7,71.4 \%)$ had invalid test results. This may not be surprising given that the manufactures' instructions were mainly text-based.

Several limitations of this study should be noted. First, our sample of participants were referred by CBOs that provided HIV testing services to MSM. However, we purposefully recruited men who were diverse in terms of age, education, and history of HIV testing. Second, we only provided HIVST kits from two manufacturers. Kits from other manufacturers might have included improved instructions. However, these two manufactures are currently the main vendors of HIVST kits in China. Third, due to the presence of an HIV testing counselor and video recording, some participants might have felt uneasy or nervous leading them to make unnecessary user errors. However, our finding is consistent with those from previous studies $[5,15]$. Finally, this was a relatively small sample of MSM participants, but the qualitative methodology (i.e., participant observation) provides contextual information of the HIVST process and is not intended to generalize. The findings could inform future surveys that quantify the error types and their magnitude.

\section{Conclusions}

Although we found that user errors were common among MSM administering HIVST, this should not deter or discourage routine implementation and scale-up of HIVST as strong evidence shows that the benefits of reaching untested MSM and increasing frequency of testing among this population outweigh the disadvantages (e.g., reduced but acceptable sensitivity). A few strategies could be implemented to facilitate the correct conduct of HIVST. First, in addition to text- and pictorial-based instructions, manufacturers should provide video instructions that use simple but clear language (e.g., OraSure Technologies provides video instructions in multiple languages). This would especially benefit men with low or limited health literacy. Second, for those who wish to access free kits through CBOs, HIV testing counselors could offer orientation or instruction before men take the kits home. Finally, health authorities should continuously and comprehensively monitor the quality of HIVST kits sold on the market so that individuals can make informed choices.

\section{Additional files}

Additional file 1: Participant observation checklist: checklist for finger prick HIV self-test. (DOC $16 \mathrm{~kb}$ )

Additional file 2: Participant observation checklist: checklist for oral swap HIV self-test. (DOC $28 \mathrm{~kb}$ )

\section{Abbreviations}

CBOs: Community-based organizations; CDC: Center for Disease Control and Prevention; HIVST: HIV self-testing; MSM: men who have sex with men 


\section{Acknowledgments}

We thank the collaborations from the community-based organizations and participants, and we would also thank the people in Jiangsu provincial CDC of China who contributed to study design and data collection for this study.

\section{Funding}

This study was supported from a grant from the National Institute of Mental Health (grant number: 1R34MH109359). The funding bodies had no role in the design of the study and collection, analysis, and interpretation of data and writing the manuscript.

\section{Availability of data and materials}

The dataset generated during and/or analyzed during the current study is not publicly available due to potential breach of confidentiality for the participants: small sample size, sensitive information (i.e., HIV-infected status), and video-recording of the procedures.

\section{Authors' contributions}

CW and HY designed the study. LY and $J$ analyzed and interpreted the data. XS and SL contributed in preparation of the checking list and informed consent of the study. CW wrote the first draft of the manuscript. All authors participated in drafting the final version of the manuscript and gave final approval to the version to be published.

\section{Ethics approval and consent to participate}

Participation in this study was voluntary and written informed consent was obtained from all participants. The study was approved by the ethics committees of UCSF, Rutgers University and Jiangsu CDC of China.

\section{Consent for publication}

Not applicable

\section{Competing interests}

CW is a member of the Editorial Board of BMC Public Health. The authors declare that they have no other competing interests.

\section{Publisher's Note}

Springer Nature remains neutral with regard to jurisdictional claims in published maps and institutional affiliations.

\section{Author details}

'Department of Social and Behavioral Health Sciences, Rutgers School of Public Health, 683 Hoes Lane West, Office 312, Piscataway, NJ 08854, USA. ${ }^{2}$ Southeast University, Nanjing, China. ${ }^{3}$ Jiangsu Provincial Center for Disease Control and Prevention, Nanjing, China. ${ }^{4}$ Peking Union Medical College, Beijing, China. ${ }^{5}$ Center for AIDS Prevention Studies, University of California San Francisco, San Francisco, USA.

Received: 16 January 2018 Accepted: 31 August 2018

Published online: 10 September 2018

\section{References}

1. World Health Organization. Guidelines on HIV self-testing and partner notification: supplement to consolidated guidelines on HIV testing services. Switzerland: World Health Organization; 2016

2. Figueroa C, Johnson C, Verster A, et al. Attitudes and acceptability on HIV self-testing among key populations: a literature review. AIDS Behav. 2015;19. 1949-65.

3. Katz D, Golden M, Hughes J, et al. HIV self-testing increases HIV testing frequency among high-risk men who have sex with men: a randomized controlled trial. Presented at: $8^{\text {th }}$ international AIDS society conference; 1922 July 2015; Vancouver, Canada; 2015.

4. Jamil M, Prestage G, Fairley $C$, et al. Access to HIV self-testing doubles the frequency of HIV testing among gay and bisexual men at higher risk of infection: a randomised controlled trial. Presented at: 21st international AIDS conference; 18-22 July: Durban, South Africa; 2016.

5. Pant Pai N, Sharma J, Shivkumar S, et al. Supervised and unsupervised selftesting for HIV in high- and low-risk populations: a systematic review. PLoS Med. 2013;10:e1001414.

6. UNAIDS. Fast-Track - Ending the AIDS epidemic by 2030. Geneva: Joint United Nations Programme on HIV/AIDS; 2014
7. Beyer C, Baral SD, van Griensven F, et al. Global epidemiology of HIV infection in men who have sex with men. Lancet. 2012;380:367-77.

8. Sullivan PS, Carballo-Dieguez A, Coates T, et al. Successes and challenges of HIV prevention in men who have sex with men. Lancet. 2012;380:388-99.

9. Beyer C, Baral SD, Collins C, et al. The global response to HIV in men who have sex with men. Lancet. 2016;388:198-206.

10. China Ministry of Health, UNAIDS, WHO. Estimates for the HIV/AIDS epidemic in China. Beijing: China Ministry of Health; 2011.

11. Zou H, Hu N, Xin Q. Beck J. HIV testing among men who have sex with men in China: a systematic review and meta-analysis. AIDS Behav. 2012;16:1717-28.

12. Han L, Bien C, Wei C, et al. HIV self-testing among online MSM in China: implications for expanding HIV testing among key populations. J Acquir Immune Defic Syndr. 2014;67:216-21.

13. Yan $\mathrm{H}$, Yang $\mathrm{H}$, Raymond HF, et al. Experiences and correlates of HIV selftesting among men who have sex with men in Jiangsu Province. China AIDS Behav. 2015;19:485-91.

14. Qin Y, Tang W, Nowacki A, et al. Benefits and potential harms of HIV selftesting among men who have sex with men in China: an implementation perspective. Sex Transm Dis. 2017:44:233-8.

15. OraSure Technologies. Final Advisory Committee Briefing Materials: Available for Public Resease. OraQuick ${ }^{\circledast}$ In-Home HIV Test. Blood Products Advisory Committee, U.S. Food and Drug Administration: Bethlehem; 2012.

\section{Ready to submit your research? Choose BMC and benefit from:}

- fast, convenient online submission

- thorough peer review by experienced researchers in your field

- rapid publication on acceptance

- support for research data, including large and complex data types

- gold Open Access which fosters wider collaboration and increased citations

- maximum visibility for your research: over $100 \mathrm{M}$ website views per year

At $\mathrm{BMC}$, research is always in progress.

Learn more biomedcentral.com/submissions 